\title{
State-offered ethnically targeted reproductive genetic testing
}

\author{
Ellen Wright Clayton ${ }^{1}$ and Kyle B. Brothers ${ }^{2}$
}

In this issue, Zlotogora et al. ${ }^{1}$ report on a program that involves state-offered carrier screening for cystic fibrosis, spinal muscular atrophy, and fragile X for the entire population of Israel, with screening for a wide array of additional diseases selected based on a combination of ethnicity, religious affiliation, and locality of origin. To their credit, Zlotogora et al. ${ }^{1}$ are quite aware that many may have ethical concerns about this program. Nonetheless, it is worth taking a moment to highlight some of the issues raised by state-offered, ethnically targeted reproductive genetic testing and to consider some of the lessons we can learn from past experience.

Offering carrier screening often is undertaken in part to diminish the frequency of disease in a population. This is particularly common when screening is offered by the state and, indeed, is a stated purpose here. This purpose, however, has always been problematic, often carrying eugenic overtones, as the ongoing debate about carrier screening for $\beta$-thalassemia makes clear. $^{2}$

Even when choices about reproductive genetic testing are formally made by couples, concerns remain. Zlotogora et al. ${ }^{1}$ report that this program is voluntary, and indeed the uptake has been variable to date. Yet in medicine, tests that are offered often become tests that are done, particularly when they are "just a blood test." One reason is that it is difficult to demonstrate that patients knowingly refused testing. Another is the impact of inertia and habituation. The state-mandated offer of maternal serum $\alpha$-fetoprotein screening to pregnant women to detect neural tube defects and aneuploidy in the fetus in California 20 years ago became so routine that some patients were unaware that it was occurring until they received an abnormal result, at times learning about the possibility while they were preparing to have an ultrasound. ${ }^{3}$ Indeed, Zlotogora et al. ${ }^{1}$ hope that uptake of this carrier screening program will soon be high throughout the country. Routinization is particularly worrisome in this context since reproductive genetic testing remains controversial. Disability rights advocates have long challenged reproductive genetic testing on an individual as well as a population basis. ${ }^{4}$ And abortion, which is inextricably involved with carrier screening, is becoming an ever more disputed topic in many countries.
Ethnically targeted screening has been particularly fraught with difficulties and is often highly politically charged. In the 1970s programs to promote sickle cell screening in the United States quickly ran into charges of racism and eugenics. ${ }^{5}$ When newborn screening for sickle cell disease was finally adopted 15 years later, a few states attempted to screen only African Americans, reasoning that such an approach was more costeffective. ${ }^{6}$ That strategy was quickly rejected because affected children were missed for a host of reasons. Clinicians and staff frequently make errors when assigning ethnicity and ancestral origin to patients, especially if they do not rely on patient selfreport. ${ }^{7}$ Ethnicity, religious affiliation, and location of origin are already imperfect surrogates for genetic diversity and will become even more so with increasing admixture. In addition, targeted screening runs the risk of reifying socially defined categories, while at the same time missing important genetic variation. Ultimately, targeted newborn screening simply became politically unacceptable in the United States, a topic other countries struggle with as well. And although Zlotogora et al. ${ }^{1}$ do suggest that a single panel will be adopted because of admixture, which will ameliorate some of the problem, they make clear that some ethnically targeted screening will remain.

While Zlotogora et al. ${ }^{1}$ report that ethnically focused screening is "well accepted" in Israel, they do not provide evidence to support this perception. It would be useful to undertake empirical research on public perceptions of this screening effort, and perhaps even to engage with various communities about this program. Even if these efforts ultimately confirm the authors' assumptions about the acceptability of this approach, these interactions will still provide benefit by helping those leading the program to develop a more nuanced understanding of the way individuals living in Israel view these issues.

Another issue presented by this program is the adverse impact of this screening strategy on women. As a strategy to reduce cost, the woman is typically screened first and her partner tested only if she is found to be a carrier. The one exception is for ultraorthodox Jews who oppose abortion. Young people are screened by Dor Yeshorim early on, but they are not informed of their personal mutational status. When a couple is contemplating marriage, they contact this program, which advises them not to proceed if they both are carriers for the

${ }^{1}$ Center for Biomedical Ethics and Society, Nashville, Tennessee, USA; ${ }^{2}$ Institute for Bioethics, Health Policy, and Law, University of Louisville, Louisville, Kentucky, USA Correspondence: Ellen Wright Clayton (ellen.clayton@vanderbilt.edu) 
same condition. Interestingly, women in this program in Israel are not screened for fragile $\mathrm{X}$ because that would make them "unmarriageable." While the authors acknowledge these issues, the fact remains these practices reinforce the notion that the mother, more than the father, is responsible for ensuring the health of the child. ${ }^{8}$

The challenges facing state-offered targeted programs of reproductive genetic testing are enduring, and they will only become more complex as multiplex screening approaches become more widely available. We must draw on what we have already learned about potential pitfalls and explore future territory carefully as we move forward in deciding how best to use the fruits of genomics research.

\section{DISCLOSURE}

The authors declare no conflict of interest.

\section{REFERENCES}

1. Zlotogora J, Grotto I, Kaliner E, Gamzu R. The Israeli national population program of genetic carrier screening for reproductive purposes. Genet Med E-pub ahead of print 16 April, 2015.

2. Cousens NE, Gaff CL, Metcalfe SA, Delatycki MB. Carrier screening for beta-thalassaemia: a review of international practice. Eur J Hum Genet 2010;18:1077-1083.

3. Press N, Browner CH. Why women say yes to prenatal diagnosis. Soc Sci Med 1997:45:979-989.

4. Raz AE. Disability rights, prenatal diagnosis and eugenics: a cross-cultural view. J Genet Couns 2005;14:183-187.

5 Reilly, P. Genetics, Law, and Social Policy. Harvard University Press: Cambridge, MA, 1977.

6. Tsevat J, Wong JB, Pauker SG, Steinberg MH. Neonatal screening for sickle cell disease: a cost-effectiveness analysis. J Pediatr 1991;118(4 Pt 1):546-554.

7. Klinger EV, Carlini SV, Gonzalez I, et al. Accuracy of race, ethnicity, and language preference in an electronic health record. J Gen Intern Med; e-pub ahead of print 2 December 2014

8. Clayton EW, Hannig VL, Pfotenhauer JP, Parker RA, Campbell PW 3rd, Phillips JA 3rd. Lack of interest by nonpregnant couples in population-based cystic fibrosis carrier screening. Am J Hum Genet 1996;58:617-627. 